\title{
Duplication Cyst of Pyloric Canal: A Rare Cause of Pediatric Gastric Outlet Obstruction: Rare Case Report
}

\author{
Dhawal Sharma • R. P. Bharany • \\ R. V. Mapshekhar
}

Received: 2 December 2011 / Accepted: 28 June 2012 / Published online: 13 July 2012

(C) Association of Surgeons of India 2012

\begin{abstract}
Duplication of the alimentary tract may occur in any site, from the mouth to the anus, and in recent years such anomalies have received wide notice. Pyloric duplication cyst is an extremely rare congenital anomaly of the alimentary tract, whose clinical presentation often mimics those of hypertrophic pyloric stenosis. Gastrointestinal duplications are observed in 1 of every 4500 autopsies, predominantly in white males. It represents $2.2 \%$ of all gastric duplications, with only 18 have been reported up to 2011 (Table 1). In most cases preoperative diagnosis is not made. We report a case of a pyloric duplication cyst in a 3-year-old girl with progressive increased vomiting. The patient had an ultrasonography, upper gastrointestinal series, and computer tomography of the abdomen. The diagnosis was confirmed by surgery and histopathology examination. The patient was asymptomatic at 12-month follow-up. The clinical and radiological analysis can reveal configurational changes consistent with a large extrinsic mass rather than muscular hypertrophy and can lead to accurate preoperative diagnosis.
\end{abstract}

Keywords Pyloric duplication $\cdot$ Hypertrophic pyloric stenosis · Gastric outlet obstruction · Enucleation · Pyloroantrectomy

D. Sharma $\cdot$ R. P. Bharany $\cdot$ R. V. Mapshekhar

Department of General Surgery,

S.B.K.S. Medical and Research Institute, Sumandeep Vidhyapeeth,

Waghodia, Vadodara, Gujarat, India

D. Sharma $(\bowtie)$

Room no.209, N.R.I. Hostel, Sumandeep Vidhyapeeth,

391760 Pipariya, Waghodia Dist-Vadodra, India

e-mail: Dhawal_sharma123@yahoo.com

\section{Case Presentation}

A 3-year-old girl, weight $10.2 \mathrm{~kg}$, was presented to us with history of abdominal fullness, pain in abdomen, and recurrent nonbilious projectile vomiting after taking feeds for 2 months. Ultrasonography of the abdomen revealed a well-defined cystic lesion in epigastric region measuring $2.7 \mathrm{~cm} \times 2.9 \mathrm{~cm}$ in close proximity to inferior surface of the left lobe of the liver. Upper gastrointestinal barium study was suggestive of narrowing of pylorus due to soft tissue opacity causing external pressure effect. CT scan was suggestive of the congenital duplication cyst at pylorus. Clinical diagnosis was idiopathic congenital hypertrophic pyloric stenosis, but radiological investigations were suggestive of the pyloric duplication cyst. The patient was prepared for elective laparotomy via transverse supraumbilical incision and externalized the pylorus. There was a cystic mass of about $5 \mathrm{~cm} \times 4 \mathrm{~cm}$ at the greater curvature of pylorus, obstructing but not communicating with the patent lumen of the pyloroduodenal canal. The cystic mass was enucleated without damage to the underlying pyloric channel and primary repair was done. The excised cyst contained yellowish mucoid fluid. On histological examination, the common wall had pyloric mucosal lining at places showing necrosis with mild chronic inflammation with fibromuscular tissue, consistent with clinical diagnosis of the congenital duplication cyst of pylorus (Figs. 1, 2, 3, 4, 5 and 6) (Table 1).

\section{Discussion}

Pyloric duplication cysts are an extremely rare congenital anomaly, with incidence of 1 in 4500, predominantly in 


\section{ULTRASONOGRAPHY}

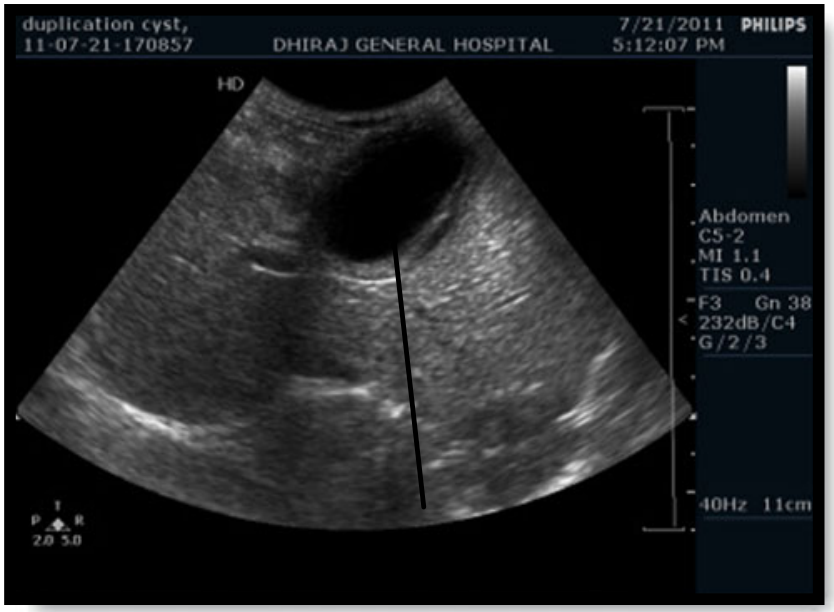

Fig. 1 A well-defined cystic lesion

white females $[1,2]$. They present with symptoms of gastric outlet obstruction and palpable mass which is clinically indistinguishable from IHPS. Enteric duplications can occur anywhere along the GI tract, but are most commonly found

\section{BARIUM STUDY}

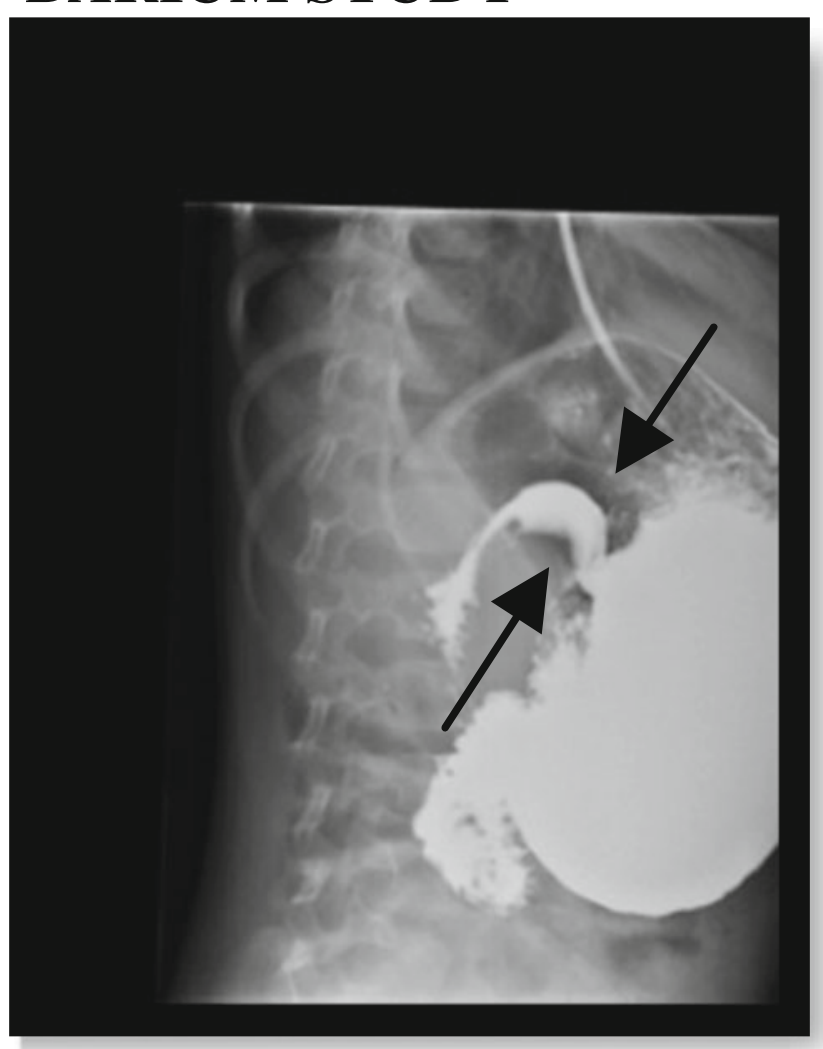

Fig. 2 Narrowing of pylorus

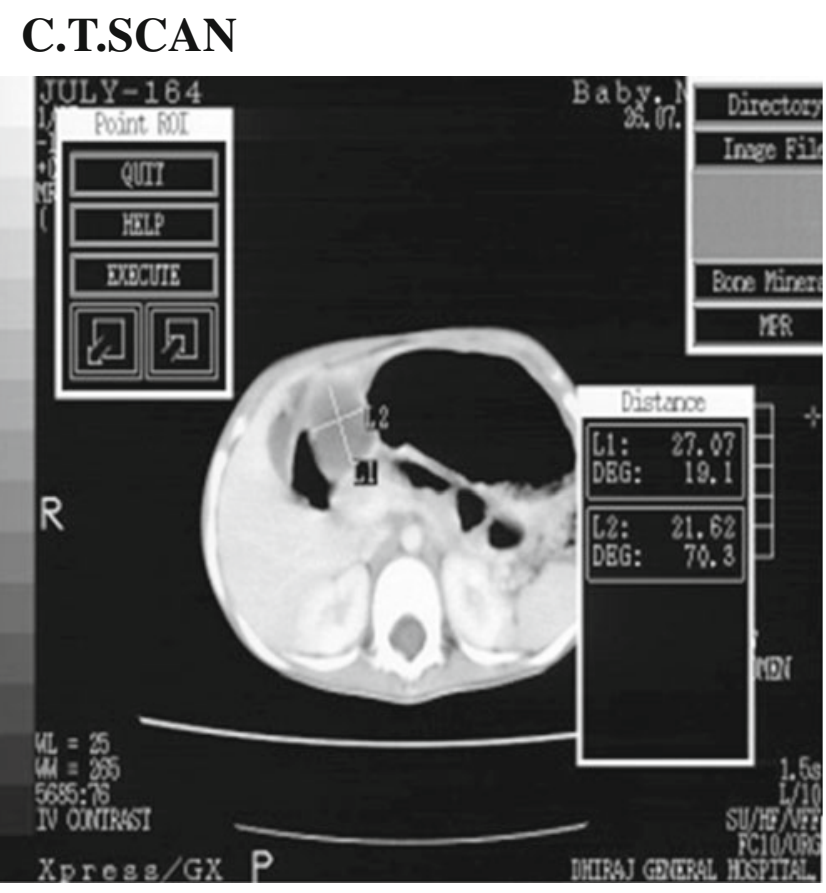

Fig. 3 A $2.7 \times 2.1 \mathrm{~cm}$ well-defined cystic lesion

in the ileum and are perhaps the rarest along the pyloric channel and represent $2.2 \%$ of all gastric duplications. The earliest case of a juxtapyloric cyst was reported by Ramsay in 1957. Till now only 18 cases have been reported so far in the English literature. In the 18 patients, excluding the present patient, with true duplication cysts, 15 presented

\section{INTRAOPERATIVE FINDINGS}

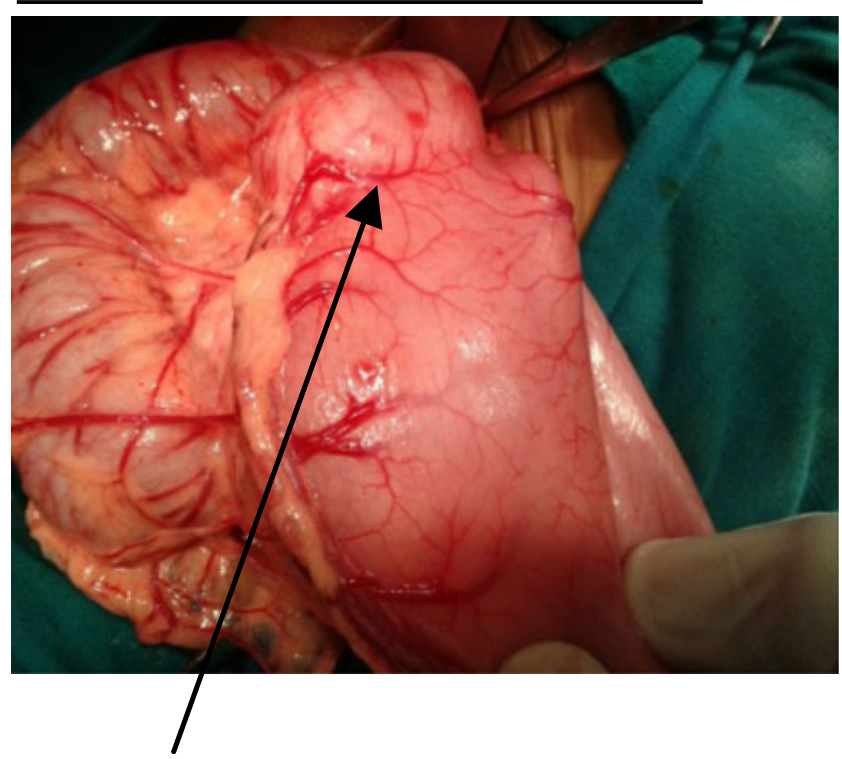

Fig. 4 Pyloric cyst at greater curvature of stomach 


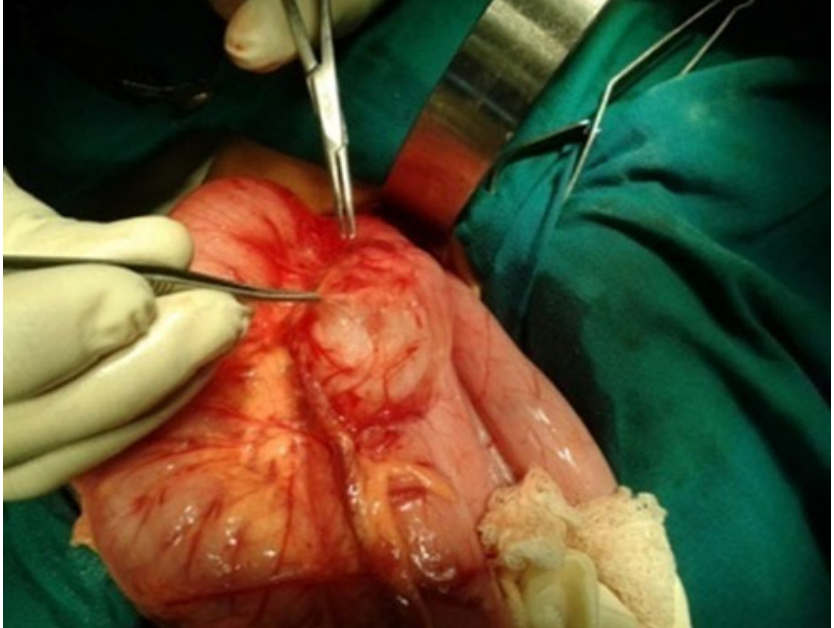

Fig. 5 Enucleation and excision of cyst

with persistent vomiting and 10 had a palpable abdominal mass. All duplications were noncommunicating. Upper gastrointestinal study may show pyloric narrowing but may not demonstrate the duplication. Ultrasound, however, will indicate the degree of pyloric hypertrophy and, if one is present, a duplication.

The etiology of duplications of this area is unknown, but the diverticulum theory of Lewis and Thyng and the Bremer theory of failure to recanalize are often mentioned; none completely explains the origin $[1,2]$. Duplications of the alimentary tract are embryologic deviations differing from

\section{HISTOPATHOLOGY}

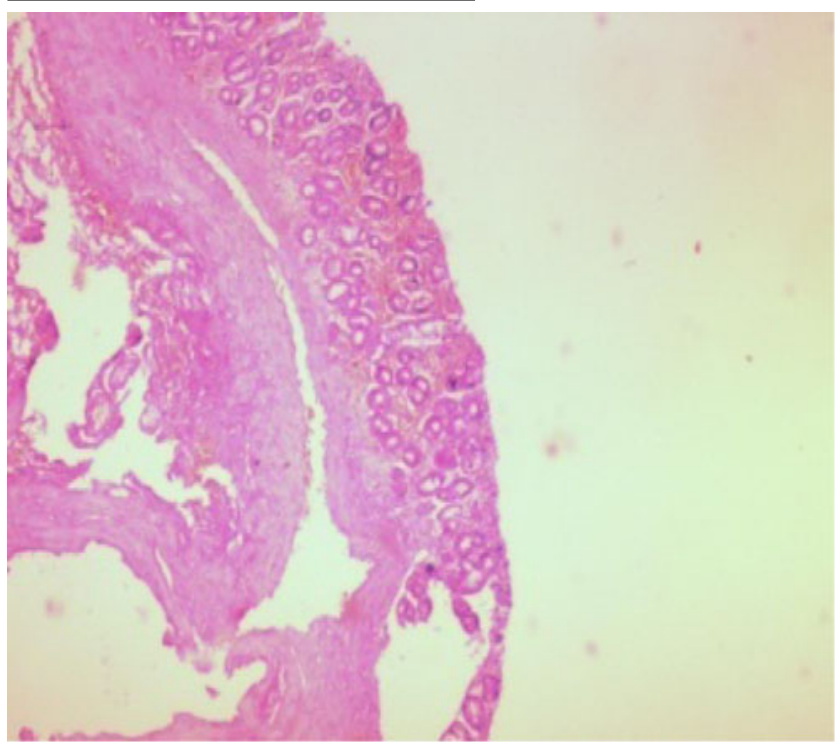

Fig. 6 Pyloric mucosal lining vitello-intestinal remnants, or dorsal enteric remnants [3]. In this respect, the theory of failure to recanalize is often mentioned in the literature and could explain to some extent the origin of pyloric duplication [2]. The most widely accepted theory has been offered by Bremer [2]. Bremer has proposed that these anomalies represent errors of canalization between week 6 and week 8 of embryogenesis.

The usual location of pyloric duplication is along the greater curvature. More often, there is no communication with the stomach. Associated anomalies can occur in up to $50 \%$ of cases and can include other alimentary tract duplications and vertebral defects [4].

The recommended criteria for diagnosis of duplication cyst include (i) proximity to the alimentary tract; (ii) common blood supply; (iii) outer smooth muscle coat sharing that is usually the gastric muscle coat; and (iv) alimentary epithelial lining (not necessarily of the adjacent gut).

Symptoms vary according to the location of the cyst and type of mucosal lining. The usual presentation is with abdominal mass, vomiting, weight loss, and failure to thrive [5]. In older children, it may present with abdominal pain, gastrointestinal bleeding, and fever [5]. These complications are attributed to inadequate drainage of the pent-up acid pepsin secretions, leading to ulceration, hemorrhage, and perforation. Although the usual age of presentation is early infancy, most are manifested by 1 year of age [5].

Surgery is the undisputed line of management but the surgical option varies. It is important that the surgery be individualized to each case. The surgeries performed have varied from simple excision to pyloroantrectomy. The stomach has blood supply on both sides unlike the mesenteric blood supply of the intestines [6]. Hence instead of resection of the involved segment of the bowel, it is sufficient to excise the cyst alone with the stripping of the mucosal lining; the raw surface being patched with transverse colon (for large defects) [6] or omentum [7], or even leaving a seromuscular gap, like following a Ramstad's pyloromyotomy [1]. This proposed "closed" approach allows for effective relief of obstruction, a rapid postoperative recovery, and the early reinstitution of feeding after $12 \mathrm{hrs}$. There are reports of excision procedures such as a limited pyloroantrectomy [8]. In all surgical procedures, it is essential to remove all the cyst lining [9]. Drainage procedures are only rarely advisable like when extensive resection would otherwise be necessary because of huge size or close proximity to the common duct etc. Procedures such as cystgastrostomy, cystenterostomy Roux-en-Y, and a "window" procedure have all been done in various situations. Marsupialization 
Table 1 List of cases till now with management

\begin{tabular}{|c|c|c|c|c|c|}
\hline Studies & Age at presentation & SEX & Size of cyst $(\mathrm{cm})$ & Diagnostic study & Surgical treatment \\
\hline Ramsay (1957) & 8 days & $\mathrm{F}$ & $3.0 \times 2.0$ & - & Local excision \\
\hline Abram \& Dennison (1961) & 7 days & $\mathrm{F}$ & 2.0 & UGI & Posterior gastrojejunostomy \\
\hline Grosfeld et al. (1970) & 3 days & M & $1.8 \times 1.0 \times 0.4$ & - & Cyst excision \\
\hline Anas \& Miller (1971) & 12 days & M & $2.0 \times 3.0$ & UGI & Cyst mucosal stripping \\
\hline Bower et al. (1978) & 3 weeks & $?$ & 1.5 & $?$ & Cyst excision \\
\hline Keramidas et al. (1980) & 20 days & $\mathrm{F}$ & $3.0 \times 2.0$ & UGI & Cyst excision \\
\hline Teele et al. (1980) & 5 months & M & Unknown & UGI AND US & Cyst excision \\
\hline Galifer \& Ferran (1980) & 11 months & M & 5.0 & UGI & Pyloroantrectomy \\
\hline Birenbaum et al. (1982) & 2 days & $\mathrm{F}$ & $2.0 \times 3.5$ & UGI AND EGD & Cyst excision \\
\hline Novak \& Boeckman (1983) & 2 months & M & $3.0 \times 1.5 \times 1.5$ & UGI AND CT & Cyst excision \\
\hline Bommen \& Singh (1984) & 1 day & M & 3.0 & UGI AND US & Cyst excision \\
\hline Tihanski et al. (1986) & 6 weeks & $\mathrm{F}$ & 5.0 & UGI & Cyst excision with Gastroduodenostomy \\
\hline Goyert et al. (1991) & Perinatal & $\mathrm{F}$ & $5.0 \times 6.0$ & US & Cyst excision \\
\hline Murty et al. (1992) & Newborn & M & $5.0 \times 8.0$ & UGI AND US & Cyst excision \\
\hline Cooper et al. (1995) & 5 weeks & M & $0.8 \times 0.5 \times 0.3$ & UGI & Cyst excision \\
\hline Manish et al. (1997) & 3 days & M & $8.0 \times 5.0$ & US & Pyloroantrectomy \\
\hline Shah et al. (2005) & 3 days & $\mathrm{F}$ & $6.0 \times 5.0$ & US & Pyloroantrectomy \\
\hline M Iwasaki et al.(2007) & 0 months & $\mathrm{F}$ & $1.4 \times 2.2 \times 1.2$ & US AND CT & Cyst excision and local excision \\
\hline Present study & 2 months & $\mathrm{F}$ & $5 \times 4$ & US AND CT & Cyst excision and local excision \\
\hline
\end{tabular}

has to be avoided because carcinoma has been found in adult duplications [4].

Asymptomatic cysts should possibly be removed because of possible late complications [5].

The results depend on the type of duplication, the presence of complications, and especially on the associated malformations [1].

\section{References}

1. Lewis F, Thyng F (1908) The regular occurrence of intestinal diverticula in embryos. Am Surg 7:505-519
2. Bremer J (1944) Diverticula and duplications of intestinal tract. Arch Pathol 38:132-140

3. Bentley JF, Smith JR (1960) Smith's accessory enteric formations. Arch Dis Child 35:87-89

4. Dudgeon DL (1993) Lesions of the stomach. In: Ashcraft Holder (ed) Paediatric surgery, 2nd edn., pp 295-297

5. Pruksopon C, Donovaan RT, Pinit A (1979) Gastric duplication. J Pediatric Surg 14:83-85

6. White JJ, Morrsan WW (1970) Improved operative technique for gastric duplications. Surgery 67:522-526

7. Grosfield J, Boles T, Roiner C (1970) Duplication of pylorus in the newborn: a rare cause of gastric outlet obstruction. J Pediatr Surg $5: 365-369$

8. Torma MJ (1974) Of double stomachs. Arch Surg 109:555-557

9. Ravitch M (1986) Duplications of the gastrointestinal tract in Welch KJ et al. Pediatr Surg 4:914-915 